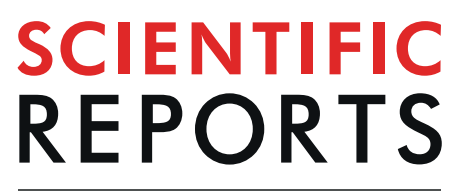

natureresearch

\title{
OPEN Waste foundry sand/MgFe-layered double hydroxides composite material for efficient removal of Congo red dye from aqueous solution
}

\begin{abstract}
Dooraid N. Ahmed ${ }^{1}$, Laith A. Naji ${ }^{2}$, Ayad A. H. Faisal ${ }^{2}$, Nadhir Al-Ansari $\mathbb{C}^{3 *}$ \& Mu. Naushad $\mathbb{C}^{4 *}$
We aimed to obtain magnesium/iron (Mg/Fe)-layered double hydroxides (LDHs) nanoparticlesimmobilized on waste foundry sand-a byproduct of the metal casting industry. XRD and FT-IR tests were applied to characterize the prepared sorbent. The results revealed that a new peak reflected LDHs nanoparticles. In addition, SEM-EDS mapping confirmed that the coating process was appropriate. Sorption tests for the interaction of this sorbent with an aqueous solution contaminated with Congo red dye revealed the efficacy of this material where the maximum adsorption capacity reached approximately $9127.08 \mathrm{mg} / \mathrm{g}$. The pseudo-first-order and pseudo-second-order kinetic models helped to describe the sorption measurements, indicating that the physical and chemical forces governed the removal process.
\end{abstract}

\begin{abstract}
The severity of water pollution has been resulted from the economic development adopted by human overall the world. The different industries such as textile, plastic, coating, and paper utilize the "dyes" in the different manufacturing stages ${ }^{1-3}$ These compounds, even at extremely low concentrations can cause a significant contamination and, consequently, the destroying of the ecosystem elements ${ }^{4-6}$. The continuous discharge of water contaminated with poisonous dyes to the environment can be formed a potential threat to the aquatic life and human health especially that the dyes are intrinsically toxic ${ }^{7,8}$. Therefore, economical and highly efficient techniques need to be developed for treatment of the contaminated water ${ }^{9-11}$. The presently available techniques include photocatalysis $^{12}$, biodegradation ${ }^{13}$, chemical coagulation ${ }^{14}$, ion exchange ${ }^{15-17}$, and adsorption ${ }^{18-22}$. The adsorption is one of the most valuable methods in the treatment of the aqueous solutions because of its high efficiency, ease of operation, low cost of operation, and easy desorption ${ }^{23-25}$. The selection or fabrication of the adsorbents is the main operative point of adsorption, where these materials must be highly stable, low cost, environment-friendly, and definitely efficient ${ }^{26,27}$. Until date, literatures have been reported different reactive materials containing activated carbon, zeolite, clay, chitosan, montmorillonite, and vermiculite ${ }^{7}$. However, several disadvantages of these materials include the high cost, poor adsorption capacity, and low reuse rate, which limits their usage ${ }^{28,29}$. Thus, finding more efficient, longer durability and low cost new adsorbents are a difficult but a vital task.

Layered double hydroxide (LDH) is a type of layered anionic compound that is joined via a non-covalent bond-an interaction between non-framework interlayer anions and positively charged main lamellar. Its general formula is $\left[\mathrm{M}^{+2}{ }_{1-\mathrm{x}} \mathrm{M}^{+3}{ }_{\times}(\mathrm{OH})_{2}\right]_{\mathrm{x}}{ }^{+}\left[\mathrm{An}^{-} \mathrm{x} / \mathrm{n} \cdot \mathrm{mH}_{2} \mathrm{O}\right]_{\mathrm{x}}^{-}$, where, $\mathrm{M}^{+3}$ is a trivalent metal ion such as $\mathrm{Fe}^{+3}, \mathrm{Cr}^{+3}, \mathrm{Sc}^{+3}$, and $\mathrm{Al}^{+3} ; \mathrm{M}^{+2}$ is divalent metal ions such as $\mathrm{Mn}^{+2}, \mathrm{Mg}^{+2}, \mathrm{Ni}^{+2}$, and $\mathrm{Zn}^{+2} ; \mathrm{An}^{-}$is an anion that balances the interlayer charge such as $\mathrm{Cl}^{-}, \mathrm{OH}^{-}, \mathrm{NO}_{3}^{-}$, and $\mathrm{CO}_{3}{ }^{-2}$; $\mathrm{x}$ is the ratio of $\mathrm{M}^{+3} /\left(\mathrm{M}^{+3}+\mathrm{M}^{+2}\right)$, varying from 0.17 to 0.33 in general ${ }^{7,30,31}$. The plenty of hydroxyl groups and the interlayer anions within the LDH can enhance the surface precipitation with metal ions ${ }^{32}$. However, the bulk/granular structure of LDHs can limit its adsorption capacity
\end{abstract}

${ }^{1}$ Department of Mathematics, College of Education for Pure Sciences, University of Kirkuk, Kirkuk, Iraq. ${ }^{2}$ Department of Environmental Engineering, College of Engineering, University of Baghdad, Baghdad, Iraq. ${ }^{3}$ Department of Civil, Environmental and Natural Resources Engineering, Lulea University of Technology, 97187, Lulea, Sweden. ${ }^{4}$ Department of Chemistry, College of Science, King Saud University, Riyadh-11451, Saudi Arabia. *email: nadhir. alansari@Itu.se; mnaushad@ksu.edu.sa 
because it is produced dense multilayered stacking. The magnetic biochar can help to offer a matrix for loading $\mathrm{LDH}$, thereby achieving extremely removal of pollutant $\mathrm{t}^{33}$.

Several kinds of LDHs were synthesized until date and utilized as reactive materials to eliminate dyes from wastewater. For instance, Yuan et al. ${ }^{34}$ proved that the calcined graphene/MgAl LDH induced the removal of hexavalent chromium ion ${ }^{34}$. Yang et al. ${ }^{35}$ used a co-precipitation to synthesize composite sorbent consisted of core-shell $\mathrm{Fe}_{3} \mathrm{O}_{4}$-LDHs and their adsorption characteristic were evaluated ${ }^{34}$. Li et al. ${ }^{36}$ synthesized $\gamma-\mathrm{AlO}(\mathrm{OH}) /$ $\mathrm{Mg}-\mathrm{Al}-\mathrm{LDH} / \mathrm{C}$ with a 3D hierarchical structure and found it to have an excellent uptake capacity for Congo red dye and minocycline in wastewater. Hierarchical porous NiCo-LDH hollow dodecahedra were synthesized via MOF-templated reactions ${ }^{37}$. The prepared NiCo-LDH can remove heavy metals anions and organic dyestuff from wastewater due to the hierarchical porous hollow dodecahedral structure and the positive charge of their surface. Lei et al..$^{38}$ certified that the $\mathrm{Cr}(\mathrm{VI})$ and Congo red can be removed effectively from wastewater by using prepared hierarchical calcined $\mathrm{Ni} / \mathrm{Mg} / \mathrm{Al} \mathrm{LDHs}^{38}$.

Waste foundry sand (WFS) is a byproduct material resulted from the metal casting industries ${ }^{39}$. In the world, there are about 35,000 foundries with an annual production of 69 million metric tons of castings. Foundries produce various kinds of wastes, such as waste sand, slug, waste chemicals, wastewater, and particulate emissions where WFS forms a huge quantity among these wastes. The American Foundry Society estimated that 6.8 million tons of foundry sand ${ }^{40}$ was disposed in landfills, which is approximately $2 / 3$ rd of the total production. There are several drawbacks of this trend, including the early closure of the material life cycle with greater consumption of virgin resources, filling of existing landfills, and subsurface contamination in unmanaged landfill, the release of contaminated leachate, economic impact, referring in particular to logistic costs in WFS transportation (because a landfill area may not be close to the foundry), and environmental impacts. Furthermore, according to the EC regulations ${ }^{41,42}$, WFS is classified as a non-hazardous waste and, consequently, it has a considerable economic value, especially in terms of iron and steel. Accordingly, the principal aim of this study was to manufacture the WFS/MgFe-LDH composite sorbent for the removal of Congo red from aqueous solutions through the application of the following steps: (1) synthesis of WFS/MgFe-LDH by co-precipitation method; (2) characterization of the prepared adsorbent; and (3) the study of the adsorption performance of Congo red.

\section{Experimental Work}

Materials. The reactive material used in the batch experiments was WFS collected from the Nasr Company for Mechanical Industries/Baghdad/Iraq. Based on the particle size distribution curve, this waste had an effective size, median size, and uniformity coefficient of $180 \mu \mathrm{m}, 320 \mu \mathrm{m}$, and 1.94, respectively. The major components of the WFS include $\mathrm{SiO}_{2}, \mathrm{Al}_{2} \mathrm{O}_{3}$, and $\mathrm{Fe}_{2} \mathrm{O}_{3}$ with the values of $94.36,2.82$, and $2.12 \%$, respectively, with low percentages of other constituents such as $\mathrm{Na}_{2} \mathrm{O}$ of $0.24 \%$ and $\mathrm{CaO}$ of $0.05 \%$. The porosity, cation exchange capacity, and bulk density of this material were $0.46,10.94 \mathrm{meq} / 100 \mathrm{~g}$, and $1440 \mathrm{~kg} / \mathrm{m}^{3}$, respectively.

In addition, to simulate the water's Congo red contamination, a solution of this dye was prepared with a concentration of $1000 \mathrm{mg} / \mathrm{L}$ and kept at the room temperature. The desired concentration of Congo red dye was obtained by dilution, and $0.1 \mathrm{M}$ of $\mathrm{HCl}$ or $\mathrm{NaOH}$ were added to set the $\mathrm{pH}$ of this solution as required.

Preparation of coated composite sorbent. LDHs were synthesized via the co-precipitation method at the room temperature. A series of $50 \mathrm{~mL}$ solution containing $\mathrm{Mg}\left(\mathrm{NO}_{3}\right)_{2} \cdot 6 \mathrm{H}_{2} \mathrm{O}$ and $\mathrm{FeCl}_{3} \cdot 6 \mathrm{H}_{2} \mathrm{O}$ with different molar ratios $(\mathrm{Mg} / \mathrm{Fe})(1 / 1,2 / 1,3 / 1,4 / 1)$ under stirring conditions was mixed with $0.3 \mathrm{~g}$ WFS for manufacturing the coated sorbent and sorption tests were conducted by using $0.1 \mathrm{~g} / 50 \mathrm{~mL}$ of prepared sorbent to specify the best molar ratio. Then, different dosages $(0.1,0.2,0.3,0.5$, and $1 \mathrm{~g} / 50 \mathrm{~mL})$ of WFS were added to the aqueous solution of the best molar ratio specified previously to obtain five types of coated sand under the effect of WFS dosage. Again, $0.1 \mathrm{~g} / 50 \mathrm{~mL}$ of prepared sorbents were applied in the sorption tests to specify the dosage of WFS suitable for manufacturing process. Drops of $\mathrm{NaOH}(2 \mathrm{M})$ and $\mathrm{Na}_{2} \mathrm{CO}_{3}(0.2 \mathrm{M})$ were added to this solution until the $\mathrm{pH}$ reached 7 after stirring for $1 \mathrm{~h}$, and the resultant material was separated by filtration and then washed with deionized water. Thereafter, the separated solids were dried at $80^{\circ} \mathrm{C}$ for $24 \mathrm{~h}$, and the efficacy of the coating process was evaluated based on the sorption capacity of Congo red for the sorbents prepared under different conditions.

Characterization of the prepared adsorbent. The crystalline structure of the prepared sorbents was examined via X-ray diffraction (XRD) (Siemens X-ray diffractometer, D8 Advance, Bruker, Germany) in Germany Laboratory/Department of Geology/College of Science/University of Baghdad. FT-IR analysis allows direct investigation of the sorption mechanisms by identifying the functional groups responsible for metal binding. Surficial morphology for coated sorbent was examined by scanning electron microscopy (SEM) equipped with an EDS (XFlash 5010; Bruker AXS Microanalysis, Berlin, Germany) operating at relative humidity of $55-60 \%$ and temperature of $21^{\circ} \mathrm{C}$ to characterize the surface topography and localization of metal on the vacant sites. EDS generates digital (compositional) maps for the adopted sorbents and the brightness in the maps is related to the intensity of the pixels for the elements in the sample. This analysis can identify element concentrations of $<0.1 \%$ microanalysis (Mira3; FEG-SEM Tescan, Czech).

Batch experiments. Batch tests were performed to get the equilibrium data and to confirm the best conditions for the treatment process. These conditions included the initial $\mathrm{pH}$, contact time and dosage. A series of $250 \mathrm{~mL}$ conical flasks were used, with each flask filled with $50 \mathrm{~mL}$ of an aqueous solution containing a certain concentration of Congo red dye. Different dosages of sorbent $(0.01-1 \mathrm{~g})$ were added to each flask, and the mixture was kept at $200 \mathrm{rpm}$ stirring on an orbital shaker (Edmund Buhler SM25; German). Then, the aqueous solution was filtered through filter paper (JIAO JIE 102); a certain volume (approximately $10 \mathrm{~mL}$ ) of the filtered solution was analyzed to measure the concentration of Congo red using an ultraviolet-visible (UV) spectrophotometer (Shimadzu Model: UV/VIS-1650) at the maximum absorption wavelength of $497 \mathrm{~nm}$. The experiments for 
specifying the best contact time were performed by withdrawing samples periodically through the time period not exceeding $60 \mathrm{~min}$. Additional tests were conducted to study the effect of initial $\mathrm{pH}$ at the range of $2-10$ on the removal efficiency of the dye with a constant concentration of Congo red $(500 \mathrm{mg} / \mathrm{L})$. The removal efficiency was calculated as follows:

$$
R=\frac{\left(C_{o}-C_{e}\right)}{C_{\mathrm{o}}} \times 100
$$

The amount of this contaminant retained in the sorbent material, $q_{e}(\mathrm{mg} / \mathrm{g})$, can be determined by ${ }^{43,44}$ :

$$
q_{e}=\left(C_{o}-C_{e}\right) \frac{\mathrm{V}}{m}
$$

Equilibrium isotherm and kinetic models for sorption data. Isotherm data for adsorption of Congo red dye by WFS/MgFe-LDH composite were modeled using the Langmuir and Freundlich isotherm models which are given as:

$$
\text { Freundlich model: } \quad q_{e}=K_{F} C_{e}^{\frac{1}{n}}
$$

where $K_{F}$ is the Freundlich constant $(\mathrm{mg} / \mathrm{g})(\mathrm{L} / \mathrm{mg})^{\frac{1}{n}}$ and $n$ is the sorption intensity ${ }^{45}$. This empirical isotherm is appropriate for multilayer sorption and heterogeneous surfaces ${ }^{46}$.

- Langmuir model (1916):

$$
q_{e}=\frac{q_{\max } b C_{e}}{1+b C_{e}}
$$

where, $q_{\max }$ is the maximum sorption capacity $(\mathrm{mg} / \mathrm{g})$ and $b$ is the affinity of the contaminant to the sorbent.

- Pseudo first-order model: This model is a popular expression that describe the sorption rate of dissolved compound from the aqueous solution and it can be written as follows ${ }^{47}$ :

$$
\frac{\mathrm{d} q}{\mathrm{~d} t}=k_{1}\left(q_{e}-q_{t}\right)
$$

By applying the conditions of $q_{t}=0$ at $t=0$ and $q_{t}=q_{e}$ at $\mathrm{t}=\mathrm{t}$, the integration of this expression can be lead to the result:

$$
\ln \left(q_{e}-q_{t}\right)=\ln q_{e}-k_{1} t
$$

The linear form of Eq. 6 can be written as below in Eq. 7 which is the Pseudo first-order model:

$$
q_{t}=q_{e}\left(1-\mathrm{e}^{-k_{1} t}\right)
$$

where, $k_{1}$ is the rate constant $(1 / \mathrm{min})$ of the Pseudo first-order.

- Pseudo second-order model: The derivation of this model is based on many assumptions; mainly, pollutant can be attached on the surface of reactive material as monolayer, the sorption energy remains the same for each reactive material, and no interaction can be occurred between the sorbed contaminants. This model illustrates as below ${ }^{48}$ :

$$
\frac{\mathrm{d} q}{\mathrm{~d} t}=k_{2}\left(q_{e}-q_{t}\right)^{2}
$$

Where, $k_{2}$ is the Pseudo second-order rate constant ( $\left.\mathrm{g} / \mathrm{mg} \mathrm{min}\right)$. Equation 8 can be integrated by applying the same conditions first-order model and the result will be as follows ${ }^{48}$ :

$$
\frac{1}{\left(q_{e}-q_{t}\right)}=\frac{1}{q_{e}}+k_{2} t
$$

By arrangement, Eq. 9 can be rewritten as in Eq. 10 which represents the Pseudo second-order formula:

$$
q_{t}=\frac{\mathrm{t}}{\left(\frac{1}{k_{2} q_{e}^{2}}+\frac{t}{q_{e}}\right)}
$$

Removal mechanisms. The kinetic models are not sufficient to recognize the mechanisms of the sorption process and this is required to apply the intra-particle diffusion model derived by Weber and Morris $(1962)^{49}$. This model is an empirical formula related between the sorbed quantity and $t^{0.5}$ rather than $t$, as shown below: 

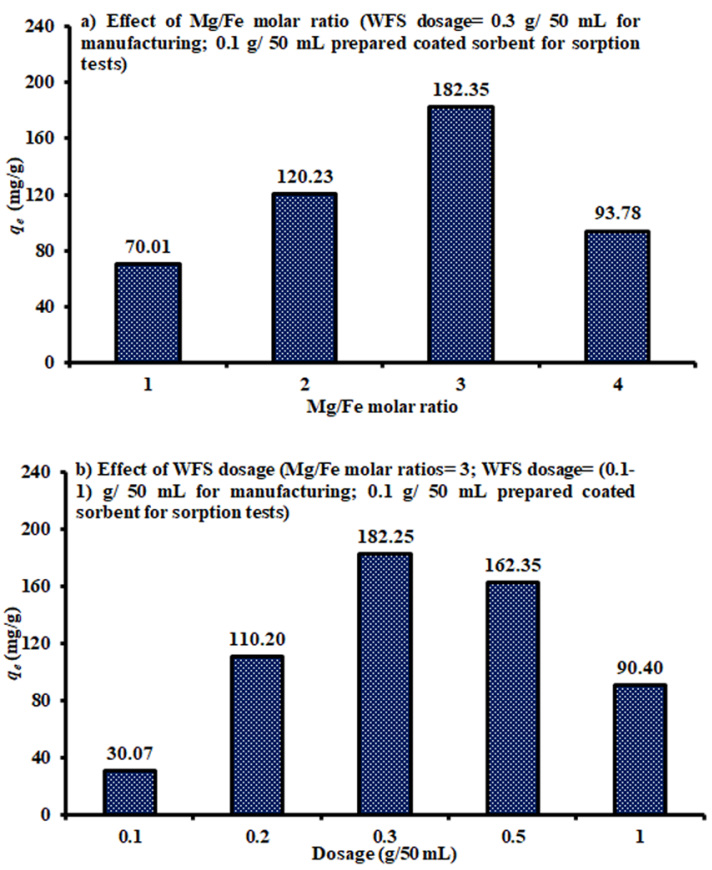

Figure 1. Sorption capacities of Congo red dye onto $0.1 \mathrm{~g} / 50 \mathrm{~mL}$ coated WFS for different $(\mathbf{a}) \mathrm{Mg} / \mathrm{Fe}$ molar ratios and $(\mathbf{b})$ dosages of prepared sorbent $\left(C_{o}=500 \mathrm{mg} / \mathrm{L} ; \mathrm{pH}=3\right.$; sorption time $=3 \mathrm{~h}$ and agitation speed $=200 \mathrm{rpm}$ ).

$$
q_{t}=k_{\text {int }} t^{0.5}+\mathrm{C}
$$

where, $k_{\text {int }}$ is the adsorption rate constant of the intra-particle diffusion model $\left(\mathrm{mg} / \mathrm{g} \mathrm{min}^{0.5}\right)$, and C is the value of intercept that tells about the boundary layer thickness.

The linear plot between $q_{t}$ versus $t^{0.5}$ means the occurrence of intra-particle diffusion mechanism and when this plot intercept with the origin, this diffusion represents the rate limiting process; otherwise, there is other mechanisms beside the intra-particle diffusion. The straight line of intra-particle diffusion is comprised of two regions: the first one is sharper and represents the instantaneous sorption or external surface sorption, while the second region is varied gradually and the intra-particle diffusion process is rate limiting.

\section{Results and Discussion}

Preparation of adsorbent. The coated composite sorbent was developed by using certain dosage $(=0.3 \mathrm{~g} /$ $50 \mathrm{~mL}$ ) of WFS mixed with different $\mathrm{Mg} / \mathrm{Fe}$ molar ratios such as $1 / 1,2 / 1,3 / 1$, and $4 / 1$. The effect of the $\mathrm{Mg} / \mathrm{Fe}$ molar ratios on the uptake of Congo red dye from the aqueous solutions onto $0.1 \mathrm{~g} / 50 \mathrm{~mL}$ of the prepared sorbent was investigated based on the sorption capacity as an indicator for the evaluation of the effectiveness of this sorbent, as plotted in Fig. 1(a). It is clear that an increase of the $\mathrm{Mg} / \mathrm{Fe}$ molar ratio causes a significant increase in the sorption capacity, and the highest value reached $182.35 \mathrm{mg} / \mathrm{g}$ occurred at a molar ratio of 3 . This figure signifies that an increase in the molar ratio beyond the value of 3 can cause a remarkable decrease in the sorption capacity; accordingly, this value can be adopted to prepare an adsorbent material for the subsequent experiments.

The next step was required to specify the quantity of WFS that must be added to prepare coated composite sorbent (i.e., WFS coated with $\mathrm{Mg} / \mathrm{Fe}-\mathrm{LDH}$ ), and this quantity has been changed within the range from 0.1 to $1 \mathrm{~g} /$ $50 \mathrm{~mL}$ using $\mathrm{Mg} / \mathrm{Fe}$ molar ratio of 3 . By addition $0.1 \mathrm{~g} / 50 \mathrm{~mL}$ of manufactured sorbent for sorption tests, Fig. 1(b) certified that an increase in the WFS dosage from 0.1 to $0.3 \mathrm{~g} / 50 \mathrm{~mL}$ can increase the sorption capacity for the contaminant under consideration from 30.07 to $182.35 \mathrm{mg} / \mathrm{g}$, respectively; then, an increase in WFS will produce a significant decrease in the sorption capacity; this behavior may be due to the limited surface of the immobilized sand. Under the same operation conditions of Fig. 1 (i.e. $C_{o}=500 \mathrm{mg} / \mathrm{L}, \mathrm{pH}=3$, sorption time $=3 \mathrm{~h}$ and agitation speed $=200 \mathrm{rpm}$ ), the sorption capacity of pristine WFS with dosage of $0.1 \mathrm{mg} / 50 \mathrm{~mL}$ was measured and reached to $29 \mathrm{mg} / \mathrm{g}$. This means that an increase in the sorption capacity of this material after coating process can be attributed to the particles of $\mathrm{Mg} / \mathrm{Fe}-\mathrm{LDH}$ precipitated on the surfaces of WFS.

Characterization of composite sorbent. Figure 2 depicts the XRD patterns of coated WFS, where the formation of a new peak can be seen at $26.6^{\circ}$, which indicates the presence of the $\mathrm{Mg} / \mathrm{Fe}-\mathrm{LDH}$ crystalline phases. This figure reveals that the synthesis of the composite sorbent consisting of WFS coated with Mg/Fe-LDH was achieved correctly. In addition, the FT-IR spectra for WFS, prepared composite sorbent, Congo red, and composite sorbent after adsorption are depicted in Fig. 3(a). The broad peak at $3390 \mathrm{~cm}^{-1}$ can be resulted from the stretching vibration of the $-\mathrm{OH}^{23,50,51}$ bonded to the inter-lamellar water, the $\mathrm{O}-\mathrm{H}$ groups of the adjacent layers, 


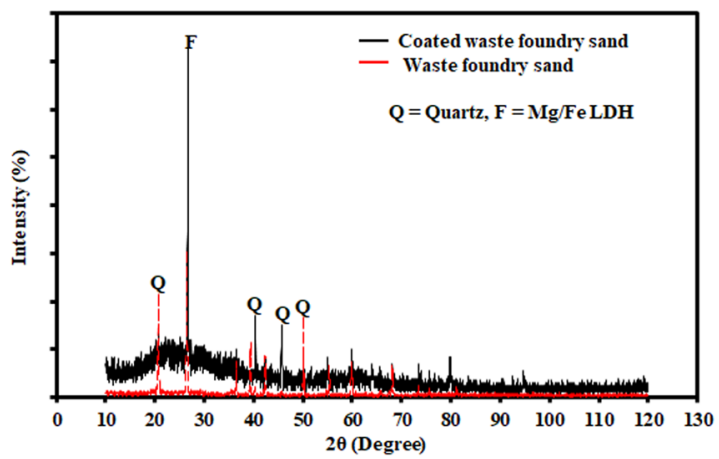

Figure 2. XRD data for WFS before and after coating with $\mathrm{Mg} / \mathrm{Fe} \mathrm{LDH}$.
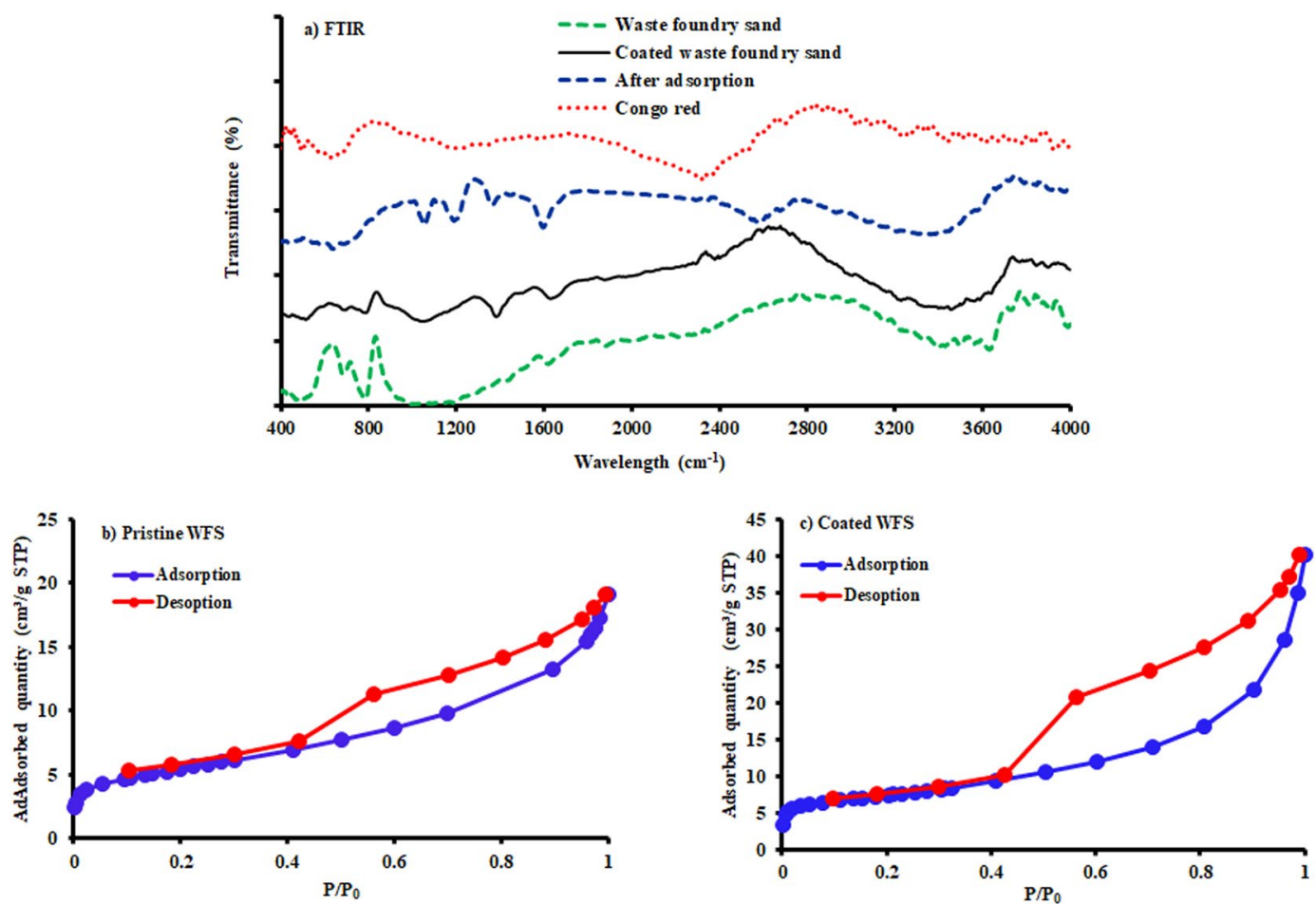

Figure 3. (a) FT-IR data for WFS, prepared composite sorbent, Congo red and composite sorbent after adsorption; (b,c) $\mathrm{N}_{2}$ adsorption-desorption isotherms.

and even the physically adsorbed water ${ }^{38}$. The peak at $1632 \mathrm{~cm}^{-1}$ is corresponded to the -OH groups of metal hydroxide and the bending vibration of the interlayer water $(\delta \mathrm{H}-\mathrm{O}-\mathrm{H})^{52,53}$. The peak nearest the $531 \mathrm{~cm}^{-1}$ is frequently accompanied to the lattice vibrations of $\mathrm{O}-\mathrm{M}-\mathrm{O}$ and $\mathrm{M}-\mathrm{O}$ (where $\mathrm{M}$ is a metal) ${ }^{36}$. In comparison with WFS, new peak at $1348 \mathrm{~cm}^{-1}$ was observed in the composite sorbent, which can be ascribed to the asymmetric stretch absorption band and the in-of-plane vibration band of the $\mathrm{CO}_{3}{ }^{-254,55}$, which suggests the successful modification of the coated sand foundry waste. After adsorption of the dye, the obtained sample displayed two evidence peaks at approximately 1080 and $1159 \mathrm{~cm}^{-1}$, which identical to the vibrations of the $\mathrm{S}=\mathrm{O}$ and the aromatic ring of Congo red molecules, respectively ${ }^{56}$. The results reveal that the Red dye can be removed successfully from aqueous solutions due to the adsorption onto the surface of coated WFS.

The specific surface area and pore size have a significant effect on the adsorption ability of the prepared sorbent. Accordingly, these characteristics are measured by conducting BET test for WFS before and after the modification process. In this regard, Fig. 3(b,c) elucidates the $\mathrm{N}_{2}$ adsorption isotherms for samples of sorbent under consideration. For relative pressure $\left(\mathrm{P} / \mathrm{P}_{0}\right)$ in the range from 0.9 to 1 , the adsorption-desorption isotherm curves of $\mathrm{N}_{2}$ for these sorbents are belonged to type IV, suggestive of mesopores type $\mathrm{H}_{3}$ hysteresis loop for coated WFS, which was the typical characteristic of slit-like pores formed by nanosheets ${ }^{57}$. At relatively low P/P. of 0.6-0.9, the type $\mathrm{H}_{2}$ hysteresis loop was appeared which identical to mesopores with ink-bottle shape. The outputs of these tests proved that the Langmuir surface area and micropore volume are equal to $84 \mathrm{~m}^{2} / \mathrm{g}$ and $0.00107 \mathrm{~cm}^{3} / \mathrm{g}$ for pristine WFS; however, these values are increased significantly for coated WFS to reach $135 \mathrm{~m}^{2} / \mathrm{g}$ and $0.00353 \mathrm{~cm}^{3} / \mathrm{g}$, respectively. 

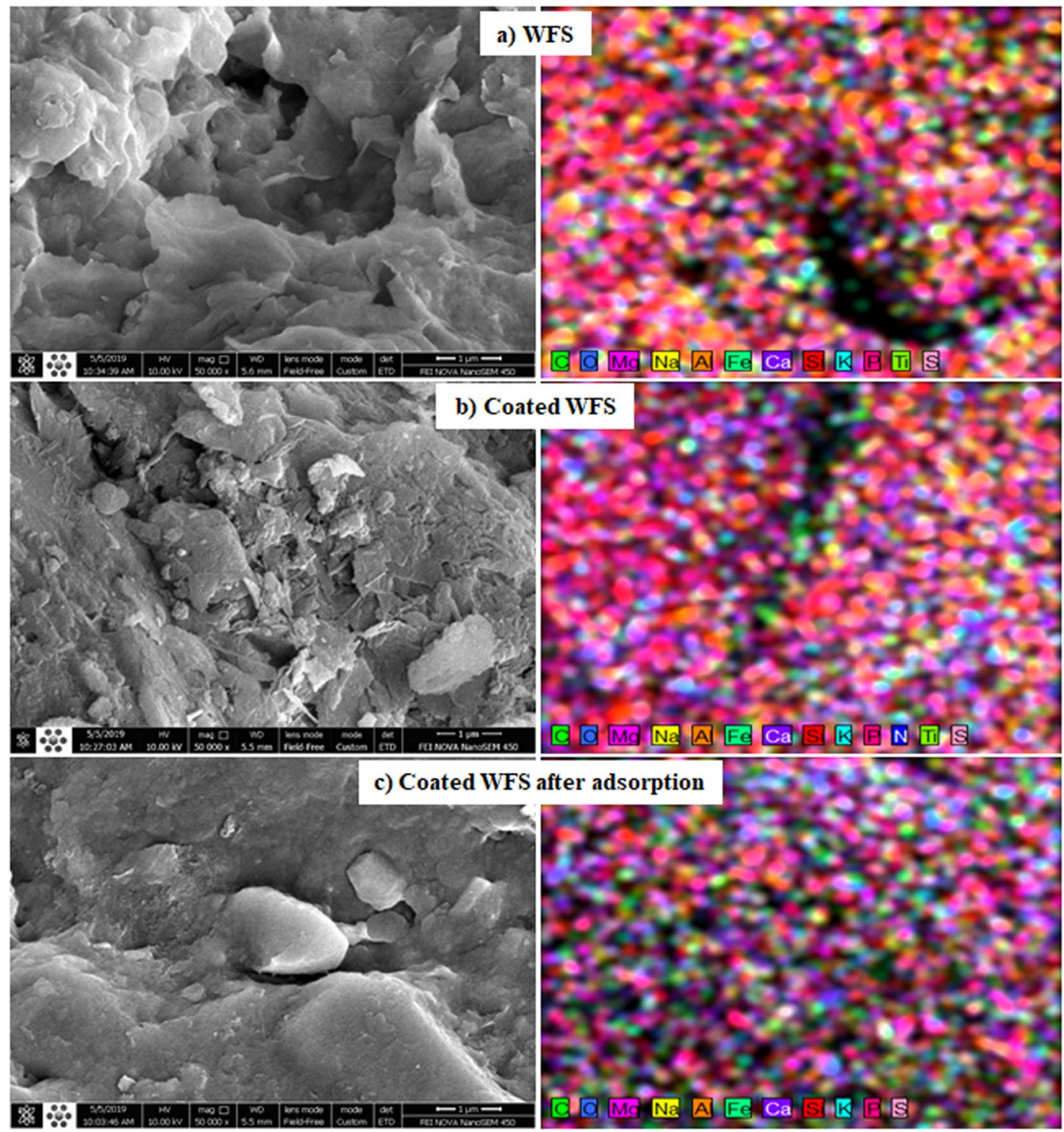

Figure 4. Scanning electron microscopy (SEM) images and EDS mapping for (a) WFS, (b) coated WFS and (c) and coated WFS after adsorption.

Figure 4 describes the surface morphology of the composite sorbent and WFS using SEM images. It is thus clear that the WFS had sharp edges and corners, rough surfaces, and compact regular pore structure. Because, the high surface area in combination with this structure, materials such as $\mathrm{F}_{3} \mathrm{O}_{4}$ and $\mathrm{Mg} / \mathrm{Fe}-\mathrm{LDH}$ can be planted on the surfaces of WFS. Figure 4 illustrates clearly that the magnetic iron particles are well dispersed on the WFS surface. The EDS mapping spectrum elucidates that there is a significant content of $\mathrm{C}, \mathrm{O}, \mathrm{Mg}, \mathrm{Na}, \mathrm{Al}, \mathrm{Fe}, \mathrm{Ca}, \mathrm{Si}, \mathrm{K}$, $\mathrm{P}$, and $\mathrm{S}$ in the WFS. After modification, the $\mathrm{Fe}$ and $\mathrm{Mg}$ with a purple dot increases dramatically and this revealing that the $\mathrm{Mg} / \mathrm{Fe}-\mathrm{LDH}$ was successfully planted on this waste. The $\mathrm{S}$ with Pink dot in the coated WFS increased significantly after the adsorption of dye, meaning that the prepared sorbent had a satisfactory uptake effect. The measurements proved that the modification of WFS by MgFe-LDH can increase its specific surface area from $19.1239 \pm 0.1063$ to $25.5344 \pm 0.1990 \mathrm{~cm}^{2} / \mathrm{g}$ due to the loading of LDHs. Furthermore, the pore size decreased from 6.828 to $4.955 \mathrm{~nm}$. All outputs of the characterization tests certify that the MgFe-LDH can increase the adsorption capacity of the prepared sorbent.

Influence of operation parameters. Figure 5(a) reveals the effect of contact time on Congo red removal efficiency using different dosages $(0.1,0.5$, and $1 \mathrm{~g})$ of coated WFS added to $50 \mathrm{~mL}$ of an aqueous solution for batch tests at the room temperature. This figure demonstrates that the removal efficiency of Congo red was significantly increased with increase in the contact time. This is because the sorption process occurs in two stages: the first one is rapid sorption due to passive surface reaction like chemical (surface complexation) or physical (electrostatic) sorption onto the adsorbent, while the subsequent stage is slow owing to the occurrence of active metabolic reaction. The slower sorption was possibly due to the decrease in the sorption sites on the surface of 

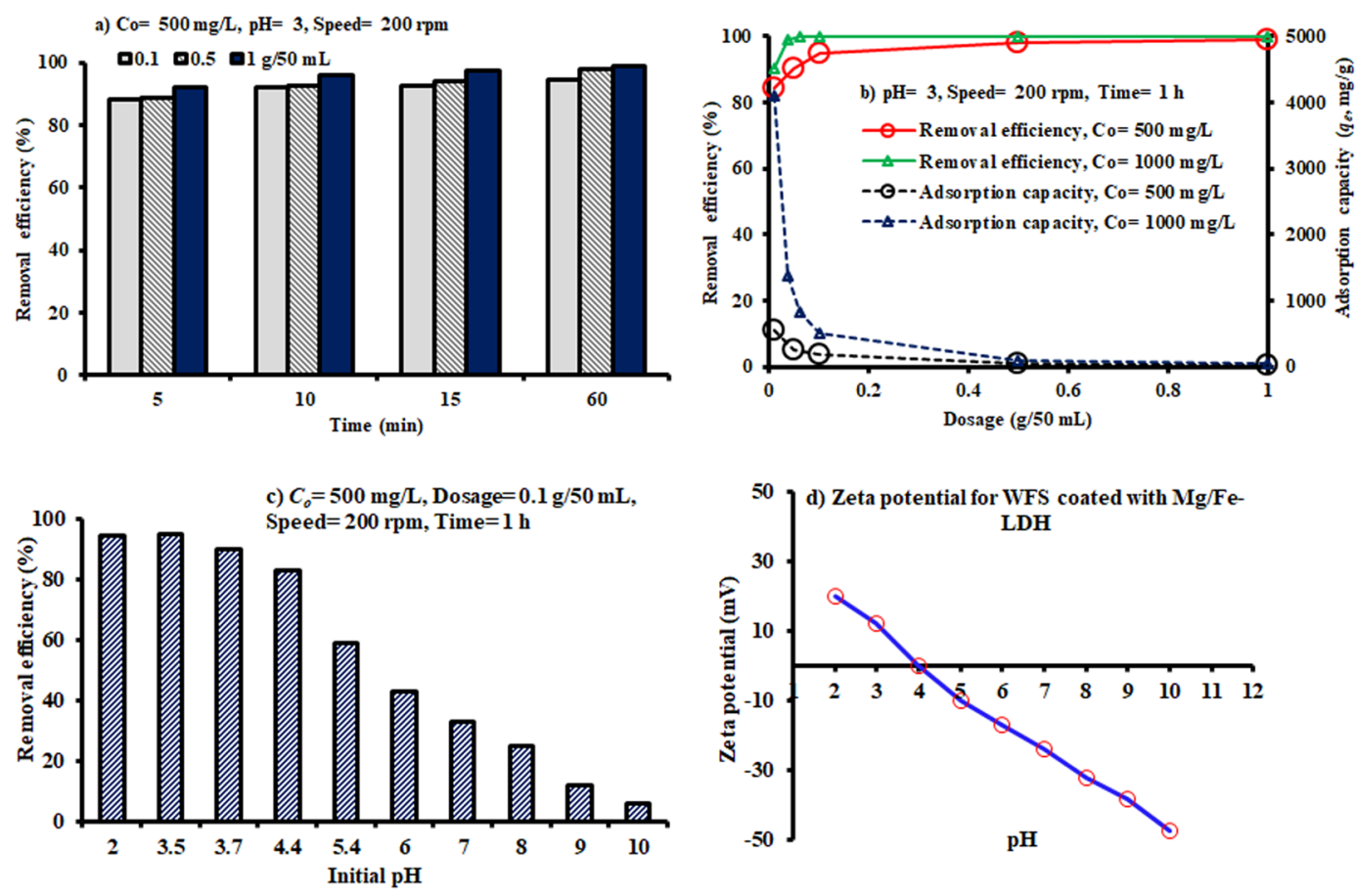

Figure 5. The effect of various operational parameters and zeta potential on the sorption of Congo red dye onto WFS coated with $\mathrm{Mg} / \mathrm{Fe}-\mathrm{LDH}$.

the adsorbent. More than $97 \%$ for $1 \mathrm{~g} / 50 \mathrm{~mL}$ was removed through $15 \mathrm{~min}$ and, in addition, the remaining concentrations of dye were relatively stabilized at a constant value beyond this time, which was adopted for the next sorption experiments.

Moreover, the dependence of Congo red sorption on the dosage of adsorbent was studied by changing the quantity of reactive material from 0.01 to $1 \mathrm{~g}$ and added to $50 \mathrm{~mL}$ of the contaminated solution, while keeping the other parameters as follows: $C_{o}=500 \mathrm{mg} / \mathrm{L}, \mathrm{pH}=3$, shaking speed $=200 \mathrm{rpm}$, and contact time $=1 \mathrm{~h}$. Figure 5 (b) illustrates that the removal efficacy was improved with increasing sorbent dosage for a fixed initial concentration because higher is the dosage of the sorbent in a solution, greater is the availability of active sites ${ }^{58}$. With further increase in the adsorbent dosage, the adsorption capacity $\left(q_{e}\right)$ was decreased significantly, while the removal efficiency showed a steady trend.

The adsorption behavior of the prepared adsorbents for different values of $\mathrm{pH}$ can be affected by many parameters such as the surface charges, adsorption capacity, and the vacant active sites. Definitely there is a large number of active sites on the surface of $\mathrm{CO}_{3}-\mathrm{LDHs}$ contains a large number of active sites, and the removal of dye is dependable on these sites as well as the dye chemistry in the solution. The adsorption of Congo red dye onto $\mathrm{Mg} /$ $\mathrm{Fe}-\mathrm{LDH}$ was studied at $\mathrm{pH}$ values 2-10 (Fig. $5 \mathrm{c}$ ). The removal efficiency was found to be nearly constant with the highest value for $\mathrm{pH}$ at the range of $2-4$, because the dye molecule exists as anion; then, the removal process decreased with a further increase in the $\mathrm{pH}$ value. A remarkable quantity of adsorption in the mentioned range means there is strong involvement of physical forces, such as hydrogen bonding, Van der Waals force, electrostatic force and hydrophopic interaction in the adsorption ${ }^{59}$. By adopting the same range of $\mathrm{pH}$ (i.e. 2-10) for sorption tests, the zeta potential was measured for composite sorbent under consideration and results are plotted in Fig. 5(d). It is obvious that the sorbent surface gets positively charged at $\mathrm{pH}<$ the point of zero charge (PZC) which equal to 4 and this will increase the removal of the negatively charged dye anions through electrostatic forces of attraction. At $\mathrm{pH}$ greater than 4 , the surface of $\mathrm{CO}_{3}-\mathrm{LDH}$ particles acquire a negative charge, which inhibits the adsorption of anion dye ${ }^{59}$. Hence, the adsorption capacity of Congo red will decrease with increasing $\mathrm{pH}$. Furthermore, the diffusion rate through the pores is also affected by the zeta-potential of the samples, and the more positive zeta-potential of adsorbent is more promising for the intra-particle diffusion.

Sorption isotherm and kinetics. Freundlich and Langmuir isotherm models were applied and fitted with the sorption measurements using nonlinear fitting within the Microsoft Excel 2016. The curves of these models are shown Fig. 6(a) and their constants have been listed in Table 1. Based on coefficient of determination $\left(\mathrm{R}^{2}\right)$ and the mentioned figure, it can be noticed that the Langmuir model is more efficient in the description of sorption data and the maximum adsorption capacity reaches to $9127.08 \mathrm{mg} / \mathrm{g}$. Table 2 presents the maximum adsorption capacity achieved in this work $(9127.08 \mathrm{mg} / \mathrm{g})$ due to the interaction of the prepared sorbent, and the solution was contaminated with Congo red dye, which is significantly higher than that achieved by different sorbents mentioned in previous studies.

In order to study the predominant mechanisms governing the removal of Congo red dye onto the prepared sorbent, pseudo-first-order ${ }^{47}$, and pseudo-second-order ${ }^{48}$ were fitted with the experimental kinetic data, as 



Figure 6. Kinetic models for sorption of Congo red dye onto WFS coated with Mg/Fe-LDH.

\begin{tabular}{|l|l|c|}
\hline Isotherm model & Parameter & Value \\
\hline \multirow{4}{*}{ Freundlich } & $K_{F}(\mathrm{mg} / \mathrm{g})(\mathrm{L} / \mathrm{mg})^{1 / n}$ & 373.93 \\
\cline { 2 - 3 } & $n$ & 2.07 \\
\cline { 2 - 3 } & $\mathrm{R}^{2}$ & 0.929 \\
\hline \multirow{4}{*}{ Langmuir } & $b(\mathrm{~L} / \mathrm{mg})$ & 0.0081 \\
\cline { 2 - 3 } & $q_{\max }(\mathrm{mg} / \mathrm{g})$ & 9127.08 \\
\cline { 2 - 3 } & $\mathrm{R}^{2}$ & 0.995 \\
\hline
\end{tabular}

Table 1. Constants of isotherm models with statistical measure for sorption of Congo red dye onto WFS coated with $\mathrm{Mg} / \mathrm{Fe}-\mathrm{LDH}$.

\begin{tabular}{|l|l|l|}
\hline Sorbents & $\boldsymbol{q}_{e}{ }^{*}(\mathbf{m g} / \mathbf{g})$ & Reference \\
\hline Coated WFS & 9127.08 & Present work \\
\hline 3D hierarchical GO-NiFe LDH & 489 & 60 \\
\hline Flower-Like NiO microspheres & 534.8 & 61 \\
\hline Core-shell Fe(OH) $)_{3}$ Cellulose & 689.65 & 62 \\
\hline $\mathrm{NiCO}_{2} \mathrm{O}_{4}$ nanosheets & 961.5 & 63 \\
\hline $\mathrm{CNT} / \mathrm{Mg}(\mathrm{Al}) \mathrm{O}$ nanocomposites & 1250 & 35 \\
\hline
\end{tabular}

Table 2. Comparison of the adsorption capacity of coated WFS in comparison with other adsorbents in the previous studies for Congo red dye. *Adsorption capacity.

plotted in Fig. 6(b,c). Nonlinear regression analysis within the "Solver" option in the Microsoft Excel 2016 was used to fit the measurements with nonlinear forms of kinetic models and finding their constants. Table 3 presents the fitted constants for these models and the coefficient of determination $\left(R^{2}\right)$, which was used to evaluate the agreement between the predicted and measured values. It is apparent from the values of $\mathrm{R}^{2}$ and the calculated adsorption capacity in comparison with the measured ones that the both kinetic models adopted in the present study were represented the sorption of Congo red dye onto the prepared sorbent in a good manner. These findings indicated that the physical sorption and chemisorption can occur together to remove the Congo red dye from aqueous solutions.

The Weber-Morris intra-particle diffusion model was applied to define whether film diffusion or intra-particle diffusion was the rate-limiting step (Fig. $6 \mathrm{~d}$ ). The model signified that the mechanism of sorption was governed by more than one mechanism and the intra-particle diffusion was not the only rate limiting step because the plot of intra-particle diffusion not passes through the origin. This means that the external mass transfer may be 


\begin{tabular}{|c|c|c|c|c|}
\hline \multirow[b]{2}{*}{ Kinetic model } & \multirow[b]{2}{*}{ Parameter } & \multicolumn{3}{|c|}{ Dosage $(\mathrm{g} / 50 \mathrm{~mL})$} \\
\hline & & 0.1 & 0.5 & 1 \\
\hline \multirow{3}{*}{ Pseudo first-order } & $k_{1}\left(\min ^{-1}\right)$ & 0.166 & 0.127 & 0.202 \\
\hline & $\begin{array}{l}q_{e}^{*}(\mathrm{mg} / \mathrm{g}) \\
q_{\exp }(\mathrm{mg} / \mathrm{g})\end{array}$ & \begin{tabular}{|l|}
178.15 \\
182.35 \\
\end{tabular} & $\begin{array}{l}43.85 \\
44.67 \\
\end{array}$ & $\begin{array}{l}23.27 \\
23.75 \\
\end{array}$ \\
\hline & $R^{2}$ & 0.959 & 0.979 & 0.983 \\
\hline \multirow{3}{*}{ Pseudo second-order } & $k_{2}(\mathrm{~g} / \mathrm{mg} \min )$ & 0.001 & 0.003 & 0.013 \\
\hline & $\begin{array}{l}q_{e}^{*}(\mathrm{mg} / \mathrm{g}) \\
q_{\text {eexp }}(\mathrm{mg} / \mathrm{g})\end{array}$ & \begin{tabular}{|l|}
197.40 \\
182.35 \\
\end{tabular} & $\begin{array}{l}49.26 \\
44.67 \\
\end{array}$ & $\begin{array}{l}25.44 \\
23.75 \\
\end{array}$ \\
\hline & $R^{2}$ & 0.993 & 0.999 & 0.997 \\
\hline \multirow{8}{*}{ Intra-particle diffusion } & \multicolumn{4}{|l|}{ First portion } \\
\hline & $\mathrm{C}$ & 50.673 & 4.097 & 6.588 \\
\hline & $k_{\text {int }}\left(\mathrm{mg} / \mathrm{g} \mathrm{min} \min ^{0.5}\right)$ & 26.603 & 8.300 & 3.987 \\
\hline & $R^{2}$ & 0.860 & 0.963 & 0.940 \\
\hline & \multicolumn{4}{|l|}{ Second portion } \\
\hline & $\mathrm{C}$ & 127.04 & 23.97 & 18.088 \\
\hline & $k_{\text {int }}\left(\mathrm{mg} / \mathrm{g} \mathrm{min} \min ^{0.5}\right)$ & 8.300 & 3.065 & 0.888 \\
\hline & $R^{2}$ & 0.986 & 0.978 & 0.992 \\
\hline
\end{tabular}

Table 3. Kinetic parameters for the adsorption of Congo red dye onto WFS coated with Mg/Fe-LDH. ${ }^{*}$ Predicted, **Experimental.

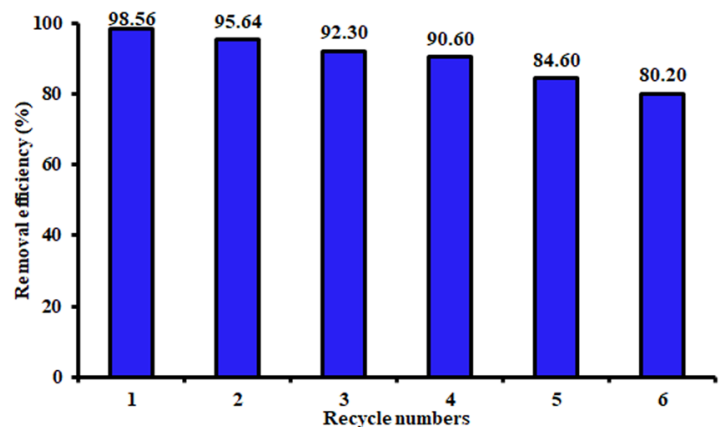

Figure 7. Removal efficiency of Congo red dye from the aqueous solution onto WFS coated with $\mathrm{Mg} / \mathrm{Fe}-\mathrm{LDH}$ in the recycle tests at room temperature for $\mathrm{pH}=3$, dosage $=0.1 \mathrm{~g} / 50 \mathrm{~mL}$ and $C_{o}=500 \mathrm{mg} / \mathrm{L}$ ).

predominant only in the initial stages of adsorption. The second linear portion was the gradual adsorption stage controlled by intra-particle diffusion ${ }^{56}$. At the initial stage, the larger slopes of the first straight line revealed that the removal rate of Congo red dye was higher because of the availability of a surface area and active sites. The lower slopes of the second portion appeared due to the reduction of the concentration gradients, indicating that the diffusion of Congo red dye in the micro-pores of sorbent takes longer, thereby reducing the rate of Congo red removal.

Recyclability. Practical application of the adsorbent depends mainly on its regeneration capacity and performance stability during the adsorption process. The recyclability tests for the composite sorbent prepared in this study were implemented by applying the sorbent sample in $\mathrm{NaOH}$ solution with concentration of $0.1 \mathrm{M}$ for $3 \mathrm{~h}$ to remove the sorbed Congo red molecules and to regenerate the exhausted adsorbent. Figure 7 presents the results of six-time recycle tests and it is obvious that the sorbent can be reused for removal of Congo red dye with efficiency exceeding $80 \%$. The results indicated that the WFS coated with $\mathrm{Mg} / \mathrm{Fe}-\mathrm{LDH}$ nanoparticle is promising sorbent in the treatment of water contaminated with anionic dye.

\section{Conclusions}

WFS coated with $\mathrm{Mg} / \mathrm{Fe}$-LDHs nanoparticle were prepared via a precipitation procedure and its adsorption performance was evaluated by a set of batch tests for the sorption of Congo red dye from wastewater. The characterization of this sorbent was achieved by XRD, FT-IR, and SEM with EDS mapping; however, these tests certified that the surfaces of WFS were rough with sharp corners and edges, where these characteristics will enhance the coating process. The tests signified that the original WFS was modified by the planting of $\mathrm{Mg} / \mathrm{Fe}-\mathrm{LDHs}$ nanoparticles. The adsorption kinetics study revealed the effectiveness of the prepared sorbent in the elimination of Congo red dye from the aqueous medium because the maximum adsorption capacity reached a significant value (approximately $9127.08 \mathrm{mg} / \mathrm{g}$ ). The pseudo first- and second-order models provided efficient description for the sorption data, which means that the physical and chemical attraction forces may be the predominant mechanisms 
in the removal process. In the future, WFS coated with $\mathrm{Mg} / \mathrm{Fe}$-LDHs nanoparticle opens new horizons in the use of such materials for the treatment of water contaminated with different types of contaminants by fixed bed columns and permeable reactive barrier technology.

Received: 3 November 2019; Accepted: 15 January 2020; Published online: 06 February 2020

\section{References}

1. Naushad, M., Sharma, G. \& Alothman, Z. A. Photodegradation of toxic dye using Gum Arabic-crosslinked-poly(acrylamide)/ $\mathrm{Ni}(\mathrm{OH}) 2 / \mathrm{FeOOH}$ nanocomposites hydrogel. J. Clean. Prod. 241, 118263 (2019).

2. Bharagava, R. N., Mani, S., Mulla, S. I. \& Saratale, G. D. Degradation and decolourization potential of an ligninolytic enzyme producing Aeromonas hydrophila for crystal violet dye and its phytotoxicity evaluation. Ecotoxicol. Environ. Saf. 156, 166-175 (2018).

3. Chowdhury, S. \& Saha, P. Adsorption Kinetic Modeling of Safranin onto Rice Husk Biomatrix Using Pseudo-first- and Pseudosecond-order Kinetic Models: Comparison of Linear and Non-linear Methods. CLEAN - Soil, Air, Water 39, 274-282 (2011).

4. Tatarchuk, T. et al. Adsorptive removal of toxic Methylene Blue and Acid Orange 7 dyes from aqueous medium using cobalt-zinc ferrite nanoadsorbents. Desalin. Water Treat. 150, 374-385 (2019).

5. Naushad, M. et al. Adsorption kinetics, isotherm and reusability studies for the removal of cationic dye from aqueous medium using arginine modified activated carbon. J. Mol. Liq. 293, 111442 (2019).

6. Sharma, G. et al. Photoremediation of toxic dye from aqueous environment using monometallic and bimetallic quantum dots based nanocomposites. J. Clean. Prod. 172, 2919-2930 (2016).

7. Hu, H. et al. Hierarchical porous $\mathrm{Ni} / \mathrm{Co}-\mathrm{LDH}$ hollow dodecahedron with excellent adsorption property for Congo red and $\mathrm{Cr}(\mathrm{VI})$ ions. Appl. Surf. Sci. 478, 981-990 (2019).

8. Peter, C. N. et al. N-doped $\mathrm{ZnO} /$ graphene oxide: a photostable photocatalyst for improved mineralization and photodegradation of organic dye under visible light. Ionics (Kiel). 25, 327-339 (2019).

9. Shrestha, R., Sharma, K., Lee, Y. R. \& Wee, Y.-J. Cerium oxide-catalyzed multicomponent condensation approach to spirooxindoles in water. Mol. Divers. 20, 847-858 (2016).

10. Thue, P. S. et al. Preparation, characterization and application of microwave-assisted activated carbons from wood chips for removal of phenol from aqueous solution. J. Mol. Liq. 223, 1067-1080 (2016).

11. Yousaf, B. et al. Enhanced removal of hexavalent chromium from aqueous media using a highly stable and magnetically separable rosin-biochar-coated TiO2@C nanocomposite.RSC Adv. 8, 25983-25996 (2018).

12. Zhu, T. et al. Synthesis of g-C3N4/Ag3VO4 composites with enhanced photocatalytic activity under visible light irradiation. Chem. Eng. J. 271, 96-105 (2015).

13. Zhuang, H. et al. Advanced treatment of biologically pretreated coal gasification wastewater by a novel heterogeneous Fenton oxidation process. J. Environ. Sci. 33, 12-20 (2015).

14. Sankar, M. S. R. et al. Kinetic, isothermal and thermodynamic investigation on electrocoagulation of Congo Red dye removal from synthetic wastewater using aluminium electrodes. Desalin. WATER Treat. 122, 339-350 (2018).

15. Lim, S. J. \& Kim, T.-H. Combined treatment of swine wastewater by electron beam irradiation and ion-exchange biological reactor system. Sep. Purif. Technol. 146, $42-49$ (2015).

16. Naushad, M. \& ALOthman, Z. A. Separation of toxic $\mathrm{Pb} 2+$ metal from aqueous solution using strongly acidic cation-exchange resin: analytical applications for the removal of metal ions from pharmaceutical formulation. Desalin. Water Treat. 53, 2158-2166 (2015).

17. Naushad, M., Mittal, A., Rathore, M. \& Gupta, V. Ion-exchange kinetic studies for $\mathrm{Cd}(\mathrm{II}), \mathrm{Co}(\mathrm{II}), \mathrm{Cu}(\mathrm{II})$, and $\mathrm{Pb}(\mathrm{II})$ metal ions over a composite cation exchanger. Desalin. Water Treat. 54, 2883-2890 (2015).

18. Shu, J. et al. Adsorption removal of Congo red from aqueous solution by polyhedral Cu2O nanoparticles: Kinetics, isotherms, thermodynamics and mechanism analysis. J. Alloys Compd. 633, 338-346 (2015).

19. Wei, X. et al. Different adsorption-degradation behavior of methylene blue and Congo red in nanoceria/ $\mathrm{H} 2 \mathrm{O} 2$ system under alkaline conditions. Sci. Rep. 9, 4964 (2019).

20. Zheng, Y., Wang, H., Cheng, B., You, W. \& Yu, J. Fabrication of hierarchical bristle-grass-like $\mathrm{NH} 4 \mathrm{Al}(\mathrm{OH}) 2 \mathrm{CO} 3 @ N i(\mathrm{OH}) 2$ coreshell structure and its enhanced Congo red adsorption performance. J. Alloys Compd. 750, 644-654 (2018).

21. Litefti, K., Freire, M. S., Stitou, M. \& González-Álvarez, J. Adsorption of an anionic dye (Congo red) from aqueous solutions by pine bark. Sci. Rep. 9, 16530 (2019).

22. Jawad, A. H. \& Abdulhameed, A. S. Mesoporous Iraqi red kaolin clay as an efficient adsorbent for methylene blue dye: Adsorption kinetic, isotherm and mechanism study. Surfaces and Interfaces 18, 100422 (2020).

23. Raghav, S., Nehra, S. \& Kumar, D. Biopolymer scaffold of pectin and alginate for the application of health hazardous fluoride removal studies by equilibrium adsorption, kinetics and thermodynamics. J. Mol. Liq. 284, 203-214 (2019).

24. Faisal, A. A. H., Al-Wakel, S. F. A., Assi, H. A., Naji, L. A. \& Naushad, M. Waterworks sludge-filter sand permeable reactive barrier for removal of toxic lead ions from contaminated groundwater. J. Water Process Eng. 33, 101112 (2020).

25. Awual, M. R., Hasan, M. M., Naushad, M., Shiwaku, H. \& Yaita, T. Preparation of new class composite adsorbent for enhanced palladium(II) detection and recovery. Sensors Actuators, B Chem. 209, 790-797 (2015).

26. Elmoubarki, R. et al. Adsorption of textile dyes on raw and decanted Moroccan clays: Kinetics, equilibrium and thermodynamics. Water Resour. Ind. 9, 16-29 (2015).

27. Farnane, M. et al. Alkaline treated carob shells as sustainable biosorbent for clean recovery of heavy metals: Kinetics, equilibrium, ions interference and process optimisation. Ecol. Eng. 101, 9-20 (2017).

28. Mahjoubi, F. Z., Khalidi, A., Abdennouri, M. \& Barka, N. Zn-Al layered double hydroxides intercalated with carbonate, nitrate, chloride and sulphate ions: Synthesis, characterisation and dye removal properties. J. Taibah Univ. Sci. 11, 90-100 (2017).

29. Al-Gheethi, A. A. S. et al. Biosorption of heavy metals and cephalexin from secondary effluents by tolerant bacteria. Clean Technol. Environ. Policy 16, 137-148 (2014).

30. Tran, H. N., Lin, C.-C., Woo, S. H. \& Chao, H.-P. Efficient removal of copper and lead by Mg/Al layered double hydroxides intercalated with organic acid anions: Adsorption kinetics, isotherms, and thermodynamics. Appl. Clay Sci. 154, 17-27 (2018).

31. Ferreira, O. P., de Moraes, S. G., Durán, N., Cornejo, L. \& Alves, O. L. Evaluation of boron removal from water by hydrotalcite-like compounds. Chemosphere 62, 80-88 (2006).

32. Zhao, D., Sheng, G., Hu, J., Chen, C. \& Wang, X. The adsorption of $\mathrm{Pb}(\mathrm{II})$ on Mg2Al layered double hydroxide. Chem. Eng. J. 171, $167-174(2011)$

33. Premarathna, K. S. D. et al. Clay-biochar composites for sorptive removal of tetracycline antibiotic in aqueous media. J. Environ. Manage. 238, 315-322 (2019).

34. Yuan, X. et al. Calcined graphene/MgAl-layered double hydroxides for enhanced $\mathrm{Cr}(\mathrm{VI})$ removal. Chem. Eng. J. 221, 204-213 (2013). 
35. Yang, S., Wang, L., Zhang, X., Yang, W. \& Song, G. Enhanced adsorption of Congo red dye by functionalized carbon nanotube/mixed metal oxides nanocomposites derived from layered double hydroxide precursor. Chem. Eng. J. 275, 315-321 (2015).

36. Li, J., Zhang, N. \& Ng, D. H. L. Synthesis of a 3D hierarchical structure of $\gamma-\mathrm{AlO}(\mathrm{OH}) / \mathrm{Mg}-\mathrm{Al}-\mathrm{LDH} / \mathrm{C}$ and its performance in organic dyes and antibiotics adsorption. J. Mater. Chem. A 3, 21106-21115 (2015).

37. Sun, C. et al. MOF-directed templating synthesis of a porous multicomponent dodecahedron with hollow interiors for enhanced lithium-ion battery anodes. J. Mater. Chem. A 3, 8483-8488 (2015).

38. Lei, C. et al. Superb adsorption capacity of hierarchical calcined $\mathrm{Ni} / \mathrm{Mg} / \mathrm{Al}$ layered double hydroxides for Congo red and $\mathrm{Cr}(\mathrm{VI})$ ions. J. Hazard. Mater. 321, 801-811 (2017).

39. Siddiquea, R., Kaur, G. \& Rajor, A. Waste foundry sand and its leachate characteristics. Resour. Conserv. Recycl. 54, 1027-1036 (2010).

40. Monosi, S., Sani, D. \& Tittarelli, F. Used Foundry Sand in Cement Mortars and Concrete Production. Open Waste Manag. J. 3, 18-25 (2010).

41. Basar, H. M. \& Deveci Aksoy, N. The effect of waste foundry sand (WFS) as partial replacement of sand on the mechanical, leaching and micro-structural characteristics of ready-mixed concrete. Constr. Build. Mater. 35, 508-515 (2012).

42. Faisal, A. A. H. \& Naji, L. A. Simulation of Ammonia Nitrogen Removal from Simulated Wastewater by Sorption onto Waste Foundry Sand Using Artificial Neural Network. Assoc. Arab Univ. J. Eng. Sci. 26, 28-34 (2019).

43. Naushad, M., Vasudevan, S., Sharma, G., Kumar, A. \& Alothman, Z. A. Adsorption kinetics, isotherms, and thermodynamic studies for $\mathrm{Hg} 2+$ adsorption from aqueous medium using alizarin red-S-loaded amberlite IRA-400 resin. Desalin. Water Treat. 57, 18551-18559 (2016).

44. Naushad, M., ALOthman, Z. A., Awual, M. R., Alam, M. M. \& Eldesoky, G. E. Adsorption kinetics, isotherms, and thermodynamic studies for the adsorption of $\mathrm{Pb} 2+$ and $\mathrm{Hg} 2+$ metal ions from aqueous medium using $\mathrm{Ti}(\mathrm{IV})$ iodovanadate cation exchanger. Ionics (Kiel). 21, 2237-2245 (2015).

45. Gheju, M. \& Miulescu, A. Sorption Equilibrium of Hexavalent Chromium on Granular Activated Carbon. 52, 1-2 (2007).

46. Ho, Y. S., Porter, J. F. \& McKay, G. Equilibrium isotherm studies for the sorption of divalent metal ions onto peat: Copper, nickel and lead single component systems. Water, Air, and Soil Pollution, https://doi.org/10.1023/A:1021304828010 (2002).

47. Lagergren, S. About the theory of so-called adsorption of soluble substances. K. Seventeen Hand 24, 1-39 (1989).

48. Ho, Y. S. \& McKay, G. Pseudo-second order model for sorption processes. Process Biochem. 34, 451-465 (1999).

49. Weber, W. J. \& Morris, J. C. Advances in water pollution research: removal of biologically resistant pollutant from waste water by adsorption. Proc. Int. Conf. Water Pollut. Symp. 2, 231-266 (1962).

50. Dhillon, A., Sapna, Choudhary, B. L., Kumar, D. \& Prasad, S. Excellent disinfection and fluoride removal using bifunctional nanocomposite. Chem. Eng. J. 337, 193-200 (2018).

51. Awual, R. et al. Schiff based ligand containing nano-composite adsorbent for optical copper (II) ions removal from aqueous solutions. Chem. Eng. J. 279, 639-647 (2015).

52. Zainuri, N. Z. et al. Palm oil mill secondary effluent (POMSE) treatment via photocatalysis process in presence of ZnO-PEG nanoparticles. J. Water Process Eng. 26, 10-16 (2018).

53. Mironyuk, I., Tatarchuk, T., Naushad, M., Vasylyeva, H. \& Mykytyn, I. Highly efficient adsorption of strontium ions by carbonated mesoporous TiO 2. J. Mol. Liq. 285, 742-753 (2019).

54. Elmoubarki, R. et al. $\mathrm{Ni} / \mathrm{Fe}$ and $\mathrm{Mg} / \mathrm{Fe}$ layered double hydroxides and their calcined derivatives: preparation, characterization and application on textile dyes removal. J. Mater. Res. Technol. 6, 271-283 (2017).

55. Jia, Y. et al. A novel magnetic biochar/MgFe-layered double hydroxides composite removing $\mathrm{Pb} 2+$ from aqueous solution: Isotherms, kinetics and thermodynamics. Colloids Surfaces A Physicochem. Eng. Asp. 567, 278-287 (2019).

56. Cheng, B., Le, Y., Cai, W. \& Yu, J. Synthesis of hierarchical $\mathrm{Ni}(\mathrm{OH}) 2$ and $\mathrm{NiO}$ nanosheets and their adsorption kinetics and isotherms to Congo red in water. J. Hazard. Mater. 185, 889-897 (2011).

57. Chen, $\mathrm{H}$. et al. Hierarchical $\mathrm{C} / \mathrm{NiO}-\mathrm{ZnO}$ nanocomposite fibers with enhanced adsorption capacity for Congo red. J. Colloid Interface Sci. 537, 736-745 (2019).

58. Sharma, G., Naushad, M., Pathania, D., Mittal, A. \& El-desoky, G. E. Modification of Hibiscus cannabinus fiber by graft copolymerization: application for dye removal. Desalin. Water Treat. 54, 3114-3121 (2015).

59. Ahmed, I. M. \& Gasser, M. S. Adsorption study of anionic reactive dye from aqueous solution to $\mathrm{Mg}-\mathrm{Fe}-\mathrm{CO} 3$ layered double hydroxide (LDH). Appl. Surf. Sci. 259, 650-656 (2012).

60. Zheng, Y., Cheng, B., You, W., Yu, J. \& Ho, W. 3D hierarchical graphene oxide-NiFe LDH composite with enhanced adsorption affinity to Congo red, methyl orange and Cr(VI) ions. J. Hazard. Mater. 369, 214-225 (2019).

61. Zheng, Y. et al. Hierarchical flower-like nickel(II) oxide microspheres with high adsorption capacity of Congo red in water. J. Colloid Interface Sci. 504, 688-696 (2017).

62. Zhao, J. et al. Fabrication and Characterization of Highly Porous Fe(OH) 3 @Cellulose Hybrid Fibers for Effective Removal of Congo Red from Contaminated Water. ACS Sustain. Chem. Eng., https://doi.org/10.1021/acssuschemeng.7b01175 (2017).

63. Bao, Y., Qin, M., Yu, Y., Zhang, L. \& Wu, H. Facile fabrication of porous $\mathrm{NiCo} 2 \mathrm{O} 4$ nanosheets with high adsorption performance toward Congo red. J. Phys. Chem. Solids 124, 289-295 (2019).

\section{Acknowledgements}

We would like to gratefully acknowledge the technical support of the Environmental Engineering Department/ University of Baghdad provided during the present work. One of the authors (Mu. Naushad) acknowledges the Researchers Supporting Project number (RSP-2019/8), King Saud University, Riyadh, Saudi Arabia for the support.

\section{Author contributions}

D.N.A., L.A.N. Contributed with experimental work in laboratory; A.A.H.F. wrote the manuscript; N.A.A. and M.N. edited the manuscript. All authors reviewed the manuscript.

\section{Competing interests}

The authors declare no competing interests.

\section{Additional information}

Correspondence and requests for materials should be addressed to N.A.-A. or M.N.

Reprints and permissions information is available at www.nature.com/reprints.

Publisher's note Springer Nature remains neutral with regard to jurisdictional claims in published maps and institutional affiliations. 
(c) (i) Open Access This article is licensed under a Creative Commons Attribution 4.0 International License, which permits use, sharing, adaptation, distribution and reproduction in any medium or format, as long as you give appropriate credit to the original author(s) and the source, provide a link to the Creative Commons license, and indicate if changes were made. The images or other third party material in this article are included in the article's Creative Commons license, unless indicated otherwise in a credit line to the material. If material is not included in the article's Creative Commons license and your intended use is not permitted by statutory regulation or exceeds the permitted use, you will need to obtain permission directly from the copyright holder. To view a copy of this license, visit http://creativecommons.org/licenses/by/4.0/.

(C) The Author(s) 2020 